\title{
The Life Esidimeni disaster
}

To the Editor: About a year ago I went to London to support my brother, who had been diagnosed with colorectal cancer. His surgery was imminent, and I could hear that he was struggling emotionally. Upon my arrival at the airport, as we sat down for a quick cup of coffee before heading home, he admitted to me that he was feeling significantly depressed and contemplating taking his own life.

For the next week I struggled to get him an appointment in the NHS's mental healthcare services. After being sent from pillar to post, at one point even told to 'go away, because neither you nor him are in the system' by a secretary at the local psychiatric hospital, I eventually managed to get him a prescription for antidepressants from a general practitioner and a referral to a psychologist.

While in London, an artist friend of mine, Raymond Westraadt, sent me a photograph of a painting he was busy with and asked my opinion as to the symbolism I saw in the painting. Given my personal experience at the time, as well as the fact that I am a public service psychiatrist, I was immediately struck by how effectively he had captured the powerlessness, pain and challenges a mental healthcare user faces.

The dilapidated wheelchair symbolising helplessness and negligence. The steel structures protruding from a wall looking eerily like gallows and an invitation for suicide. The political poster with its empty promise of 'working together we can do more'. Seeing the early stages of the painting and the emotions it evoked, I immediately agreed to buy the painting.

Shortly after Raymond learnt of the crisis in Gauteng regarding the death of 94 mental health care users, he posted the following on his Facebook wall: 'Little did I know of the impending crisis that was looming when I painted this image. I am now nauseated and disturbed as I follow the unfolding tragedy of the 94 mentally ill patients who died at the hands of the Gauteng Department of Health. DISGUSTED!!'.

I know that all of us in the psychiatric fraternity in South Africa (SA) are appalled by what happened in Gauteng, and our thoughts are with the families of the deceased patients, as well as with our colleagues there who had to deal with the aftermath of this disaster.

The National Mental Health Policy Framework and Strategic Plan 2013 - 2020 contains a wonderful picture of what our mental health services could look like, and yet, in the province I work in, I am desperately worried that not only are we nowhere near implementing this plan, we are in fact regressing evermore into a state of defectiveness. I cannot help but think our local services are heading towards a similar disaster to the one in Gauteng.

We, as public service psychiatrists, can do so much more, but our hands are tied by cutbacks and bureaucracy and empty promises. It would appear that, inasmuch as our mental healthcare users are facing challenges in South Africa, in my experience it is not much better in the UK. Paying lip-service to what can be achieved together by politicians, regardless of their affiliation to a specific political party, seems to be the case elsewhere in the world as well, while those with mental illness continue to suffer.

I sincerely hope that the over 100 deaths will not be in vain, and that one day we will look back and say that that was the year that politicians in South Africa started taking the plight of the mentally ill seriously.

PS: The author obtained permission from both his brother as well as the artist prior to publication.

\section{Grobler}

Head, Clinical Unit, Elizabeth Donkin Hospital, Port Elizabeth, Eastern Cape, South Africa; Associate Professor, Walter Sisulu University, Mthatha, Eastern Cape, South Africa; and Research Associate, Nelson Mandela University, Port Elizabeth, Eastern Cape, South Africa.

dr.stof@mweb.co.za

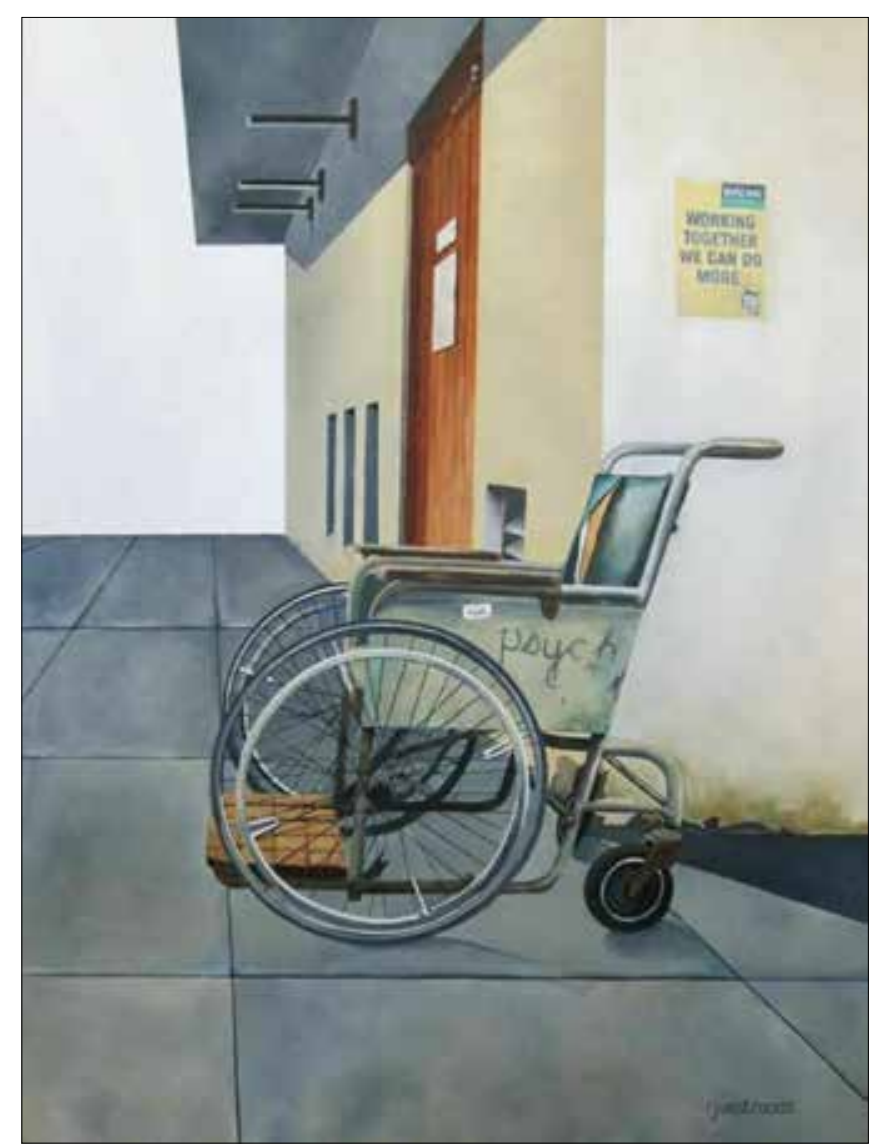

